\title{
PAN. EL VAGABUNDEO DEL MÚSICO PASTOR
}

\author{
María Cecilia Colombani ${ }^{1}$
}

\begin{abstract}
“Dans les représentations comunes, le 'féminin' et le 'masculin' sont appliqués aux apparences ou aux comportementes des individus: les vêtements, le maquillage, les gestes, la voix, le type d'activité professionnelle, sexuelle ou physique peuvent être qualifiés de 'féminins' et 'masculins' - et ce, qu' il s' agisse d' hommes ou de femmes" (BOEHRINGER, S.; SEBILLOTE CUCHET, V.: 2011, p. 15).
\end{abstract}

\begin{abstract}
Resumen: El proyecto del presente trabajo consiste en recorrer el Himno Homérico XIX a Pan a fin de relevar ciertas marcas identitarias y algunos aspectos funcionales de Pan, una divinidad desconocida para Homero y Hesíodo que no lo nombran en sus referencias a los Olímpicos. Aparece como un dios cornudo, con patas de cabra, de imagen lasciva, peligroso e irascible, inscrito en el límite de la tensión entre naturaleza y cultura.

Proponemos una primera aproximación a su imagen de la mano del soporte cerámico como modo de cruzar dos lenguajes, dos órdenes discursivos, con sus reglas propias de funcionamiento, dos logoi que, en su entrecruzamiento textual, nos permitirán un acceso más profundo a la materialidad del tópico. Desde esta perspectiva, los "vasos" hablan, constituyen un soporte de imaginería que nos permite acercarnos a la representación de Pan, de modo análogo a la entrada que nos habilitan las fuentes, que analizaremos paralelamente.

Palabras clave: Pan, Himno homérico a Pan, figuras rojas, mismidad, otredad.
\end{abstract}

\section{INTRODUCCIón}

El proyecto del presente trabajo consiste en recorrer el Himno Homérico XIX a Pan a fin de relevar ciertas marcas identitarias y algunos aspectos funcionales de Pan, una divinidad desconocida para Homero y Hesíodo que no lo nombran en sus referencias a los Olímpicos. Aparece como un dios cornudo, con patas de cabra, de imagen lasciva, peligroso e irascible, inscrito en el límite de la tensión entre naturaleza y cultura. Divinidad relativamente reciente, que

1 Professora da Facultad de Filosofía, Ciencias de la Educación y Humanidades (Universidad de Morón) e da Facultad de Humanidades (Universidad Nacional de Mar del Plata). E-mail:ceciliacolombani@hotmail.com. 
no aparece en fecha antigua, siendo se primera mención en Epiménides, fr. 16, que refiere a Calisto como su madre.

$\mathrm{Su}$ origen se sitúa en la Arcadia, región del Peloponeso, donde hay referencias de un culto en honor al dios a partir del siglo VI a. C., aunque se supone que se trata de un culto local de larga data. Tal como sostiene Bernabé Pajares, "Nacido entre comunidades pastoriles, Pan es pastor él mismo, y presenta los rasgos propios de la vida del pastor: el aislamiento, la afición musical, e incluso la siesta" (2001, p. 219). La primera inscripción que podemos intuir es espacial ya que su ámbito es el topos rural y pastoril.

A menudo se lo nombra en plural, Panes, como ocurre con Sileno, que también aparece nombrado como Silenos, con quien tiene algunos rasgos en común, sobre todo a partir de su parecido físico. Según Bernabé Pajares este plural hace verosímil la idea de que se trata, no de una divinidad tradicional, sino de un conjunto de divinidades naturales que luego toman forma individual a partir de las exigencias del culto.

\section{LA EXPERIENCIA TRÁGICA}

Proponemos una primera aproximación a su imagen de la mano de la cerámica roja como modo de intersectar dos lenguajes, dos órdenes discursivos, con sus reglas propias de funcionamiento. Desde esta perspectiva, los vasos hablan, constituyen un soporte material e imagético que nos permite acercarnos a la representación de Pan, de modo análogo la entrada que nos habilitan las fuentes.

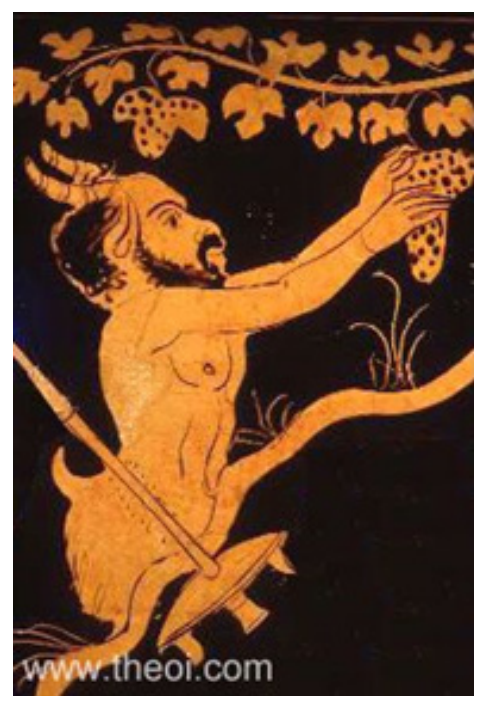

Museum Collection: Toledo Museum of Art, Toledo, Ohio, USA Catalogue Number: Toledo 1981.110 Beazley Archive Number: N/A Ware: Lucanian Red Figure Shape: Volute krater Painter: Attributed to the Creusa Painter Date: ca 380 - 360 BC Period: Late Classical. Para la totalidad de los vasos remitirse a www.theoi.com. Theoi Project Copyright 2000-2011, Aaron Atsma. 
La cerámica nos devuelve así esta primera imagen de Pan. Si bien el vaso completo recoge la pareja que constituyen Dioniso y Ariadna enlazados en una cueva, nuestro intento radica en mostrar esta primera representación de nuestro personaje. Precisamente, en la cima de la cueva, Pan está recogiendo uvas. Sólo se representa la parte superior de su cuerpo y la sección media y el comienzo de la parte inferior, mostrando una figura animalizada semejante a la de una cabra. Un delgado engobe cubre su cabello, su barba y su bigote, y finas líneas marcan las crestas de su cuerno.

En esa corporeidad peculiar, Pan se halla a mitad de camino entre lo humano y lo animal; desde ese espacio ontológico, podemos apreciar su torso y sus piernas con forma de cabra. Son visibles hileras de puntos finos en cada lado del pie del cótabo que es sostenido por una ménade detrás de él.

Sin duda, estamos ante una figura del borde, del límite y de los confines entre un reino, el humano, y otro de connotaciones diferentes, el animal. Pan parece estar en las fronteras de esos topoi y la imagen repone precisamente esa figura distorsionada, vecina de las formas de la Otredad. La cerámica se convierte así en el logos que inscribe una primera presentación en sociedad.

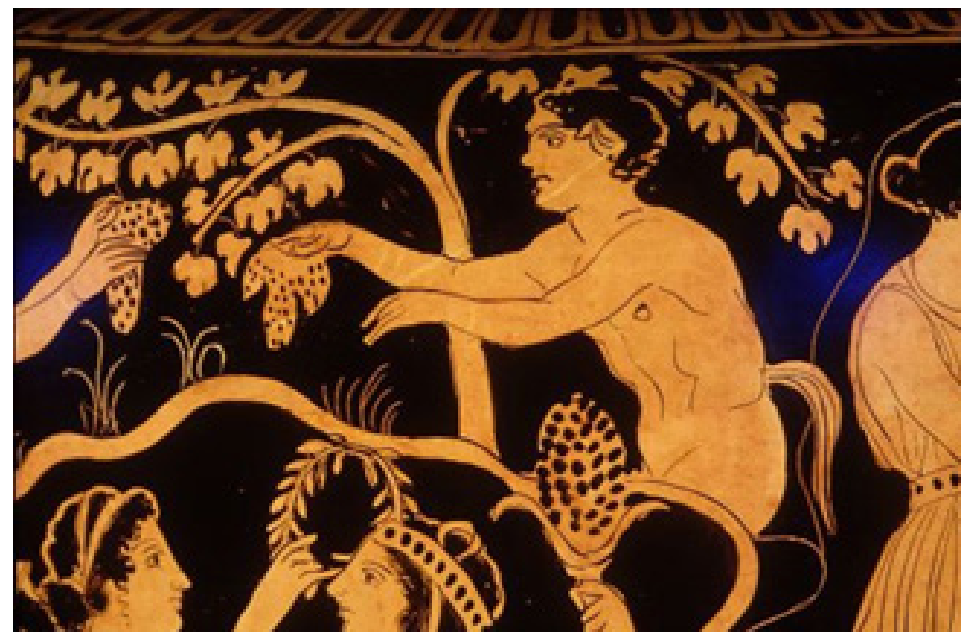

Museum Collection: Toledo Museum of Art, Toledo, Ohio, USA Catalogue Number: Toledo 1981.110 Beazley Archive Number: N/A Ware: Lucanian Red Figure Shape: Volute krater

Painter: Attributed to the Creusa Painter Date: ca 380 - 360 BC Period: Late Classical. Para la totalidad de los vasos remitirse a www.theoi.com. Theoi Project Copyright 2000-2011, Aaron Atsma.

La pieza nos invita a asociar la figura de Pan con la de los sátiros, reforzando con ello el vínculo que queremos establecer entre ciertas figuras que representan criaturas limítrofes entre lo humano y lo animal. La 
continuidad de la imagen nos marca la presencia de un sátiro que llega, desde la izquierda, para ofrecerle un racimo de uvas, próximo a la parra en la que Pan está arrancando sus propias uvas. Las piernas del sátiro también son invisibles, quedando ocultas detrás de la colina y la cueva.

Enfrentados cara a cara, ambas criaturas completan el mapa de lo Otro en materia de figuras que mezclan los topoi, intersectando con sus marcas identitarias rasgos de lo humano pero también de lo bestial. Las imágenes siguen hablando desde su elocuencia plástica, desde su propio discurso, emparentado con la capacidad sensible de ver aquello que el soporte textual sugiere desde otro logos. La cerámica se convierte así en una posibilidad sensible de recortar el objeto en análisis desde otro andarivel, desde otra mirada, desde otro punto de instalación material y simbólico.

Los vasos "hablan", "cuentan", "muestran" y con ello se convierten en magníficos soportes materiales de una realidad. Finalmente, una tercera presencia para completar la trilogía de personajes que parecen constituir una forma de lo Otro: las ménades, presentes en la representación plástica.

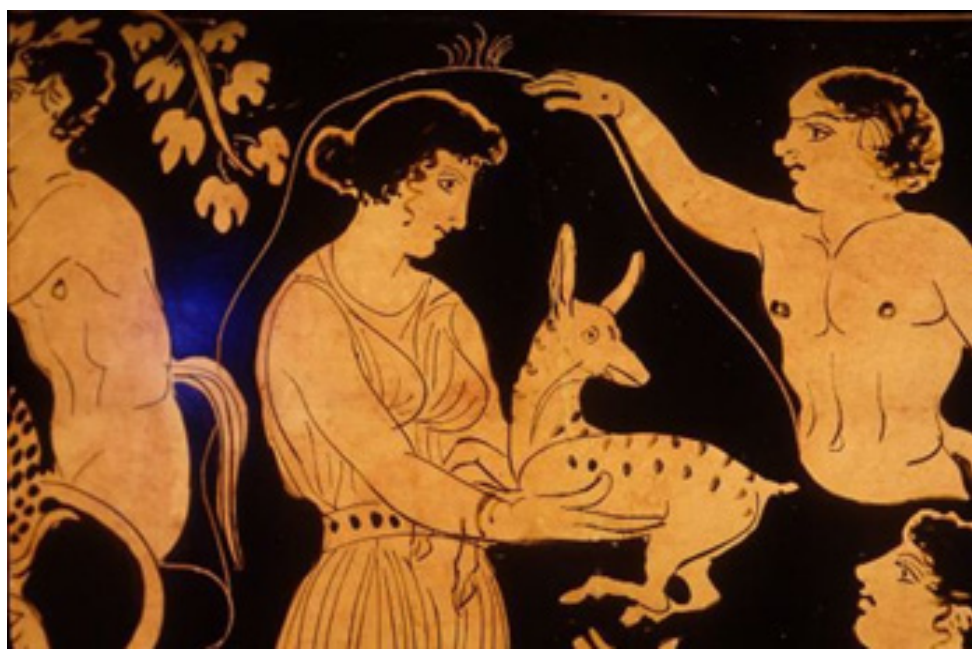

Museum Collection: Toledo Museum of Art, Toledo, Ohio, USA Catalogue Number: Toledo 1981.110 Beazley Archive Number: N/A Ware: Lucanian Red Figure Shape: Volute krater Painter: Attributed to the Creusa Painter Date: ca 380 - 360 BC Period: Late Classical.

A la derecha de la cueva se alza una ménade que mira hacia la derecha, sosteniendo un cervatillo en ambas manos y ofreciéndolo a otra ménade sentada. La que está de pie usa un chitón transparente hasta la rodilla marcado en las rodillas por una banda, zapatos y brazaletes. El chitón está ceñido a 
la cintura, y los puntos cubren el cinturón. Se trata, en última instancia, del hábito tradicional que caracteriza, como marca identitaria, al colectivo, tan cercano a la figura de Dioniso, hasta representar su proprio thíasos. El cabello de la ménade, menos la vincha, es idéntico al de Ariadna, con un rodete en la nuca y un mechón rizado frente a la oreja.

El cervatillo, que gira la cabeza bruscamente hacia atrás, tiene puntos que marcan su lomo y su pescuezo. La ménade sentada alza ambos brazos para recibir al animal, figura familiar a las ménades, también territorializadas en un topos de alteridad identitaria que las retira de las marcas habituales del colectivo femenino para arrojarlas a una extraña foraneidad ontológica, vecina a la bestialidad y la animalización.

Ella también viste un chitón asegurado a la cintura por un cinturón punteado, zapatos y brazaletes, así como un collar. Pan, los sátiros y las ménades. Trilogía de Otredad que la pieza ha mostrado desde sus reglas discursivas.

Lo Otro cobra, en el soporte material de la cerámica roja la visibilidad de una familiaridad estructural frente a las formas conservadas de lo Mismo. Pan y sus vecinos irrumpen desde su extrañeza radical para tensar las relaciones entre lo Mismo y lo Otro. Apenas un recorte del universo imagético para mostrar otro logos, otro discurso capaz de exhibir las marcas identitarias de los personajes que estamos transitando.

Como aporte, estamos intentando poner en diálogo dos modelos discursivos y, por ello, apelamos, en este primer momento, a la utilización de imágenes rojas. Apenas un mínimo atajo ilustrativo para dar cuenta de su importancia en el marco de las prácticas sociales que marcaron el período clásico.

En el trabajo de madurez de Exequias la técnica de figuras negras alcanzó - y quizá sobrepasó- sus límites, y los artistas, interesados en los nuevos problemas de una anatomía más natural y la expresión de estados de ánimo, necesitaron un medio más libre. Lo encontraron en la técnica de figuras rojas, por la cual la figura era dibujada en delineado sobre un campo claro, los detalles interiores marcados por el pincel en vez del buril, y el fondo relleno con negro sólido. Algo de esto era inevitable. Delinear con detalles pintados lineales era una práctica común en la pintura libre y una variación ocasional en la cerámica contemporánea de figuras negras; los artistas de figuras negras utilizaban detalles negros sobre figuras pintadas en blanco; y el fondo negro, deseable en sí mismo para dar al dibujo la preeminencia en las superficies replegadas de una vasija, tenía paralelo en la escultura con relieve (en donde 
el fondo estaba coloreado en rojo o azul), así como en algunas losas pintadas.

La cuestión importante no es cómo, sino por qué los artistas vinieron a elegir la técnica de las figuras rojas; pues fue una elección hecha por los artistas a su medida y no para satisfacer el mercado, en el que, por otra generación o más, las figuras negras fueron populares como siempre.

El estilo de figuras rojas se basaba en el dibujo lineal, independiente del color o el sombreado, pero (lo que no es siempre evidente en las reproducciones familiares en blanco y negro) se distinguían rápidamente dos tipos de líneas. Una es la línea plana, que puede estar diluida a un marrón claro. Pero para enfatizar los detalles mayores los pintores de vasos preferían una fina arruga de negro brillante que puede sentirse con el dedo.

Esta no era una nueva invención, ya que por una generación había sido popular en las figuras negras en lugares humildes como las divisiones en bandas de los patrones en lengua; pero su importancia es nueva y otorga una precisión peculiar a las primeras obras de figuras rojas. No se renunció a la incisión por entero; por alrededor de treinta años fue comúnmente usada para delinear el cabello negro contra el fondo negro, y aparece incluso más tarde. El accesorio de color fue por un siglo aplicado con mucha modestia. El púrpura era conveniente para tales cosas como filetes y para las inscripciones en el campo en el que reservar las letras habría sido fastidioso; pero el blanco es raro, incluso para el cabello de los hombres viejos.

A finales del siglo $\mathrm{V}$ un gusto por la ornamentación brotó en adornos blancos y dorados, y más tarde el blanco siguió siendo usado con libertad para la piel. En ocasiones un marrón lavado de pintura diluida seleccionaba una pequeña área. Otros colores aparecen ahora y entonces, en particular en obras influenciadas por la pintura libre, y se vuelven regulares en la cerámica de fondo blanco de mediados y finales del siglo $\mathrm{V}$.

\section{Intersectando los logoi. De la cerámica al Himno}

La variedad de versiones en torno a su filiación de Pan es significativa. En el Himno aparece como hijo de Hermes, pero en otras tradiciones míticas como hijo de Zeus, de Apolo y hasta de Crono. Su función principal, inscrita en el poder al que está asociado, es suscitar el pánico, el terror irracional que puede capturar a grupos enteros; por ese motivo su presencia en el combate es fundamental cuando provoca ese sentimiento en el enemigo al que hay que vencer. El miedo lo desarma y constituye un factor importante de la victoria. 
Se trata de un Himno de extensión media, con un apartado dedicado a las características del dios y a sus distintas funciones e inscripciones espaciales, su misión de pastor, de músico, de conductor del coro de las ninfas. Más tarde se expone su nacimiento como relato del canto de las musas, que encadena distintos acontecimientos, el amor de Hermes, el nacimiento de su hijo, Pan, la huida de la nodriza y la llegada del recién nacido al Olimpo para ser presentado ante los Inmortales.

El Himno se cierra con el habitual saludo y una fórmula de transición.

\section{Vayamos al Himno}

Háblame, Musa, del amado vástago de Hermes, el caprípedo, bicorne, amante del ruido, que va y viene por las arboladas praderas junto con las Ninfas, habituadas a las danzas. Caminan ellas por las cumbres de la roca, camino de cabras, invocando a Pan, el dios pastoral de espléndida cabellera, desgreñado, bajo cuya tutela se hallan todas las nevosas colinas, así como las cimas de los montes y los senderos pedregosos (HOMERO, Himno XIX, 1-8)

La experiencia poética supone, como sabemos, una invocación a la Musa como condición de posibilidad del canto poético. Las Musas son, en la Teogonía hesiódica, hijas de Mnemosýne, y aparecen como el elemento divino que inspira y "realiza" la función poética. La asociación de las Musas con la función poética nos lleva a hacerlas jugar en una dualidad de tópoi: su vinculación con los dioses y su acción con los hombres. Imprescindibles para la función poética, son sostenedoras del orden y la justicia cósmica, ya que sin ellas, no hay canto poético. Así lo expresa Homero: "Decidme ahora, Musas, dueñas de olímpicas moradas, pues vosotras sois diosas, estáis presentes y sabéis todo, mientras que nosotros sólo oímos la fama y no sabemos nada, quiénes eran los príncipes y los caudillos de los dánaos" (HOMERO, Ilíada, II, 483-486).

Dignas hijas de una madre que lo sabe todo; figuras femeninas necesarias y funcionales a los designios del Padre de hombres y dioses, las Musas resultan aliadas incondicionales de su padre en su gesta fundacional del orden, que tanto ha costado instaurar. Las primeras marcas identitarias responden a tres órdenes de relaciones; una dimensión atributiva donde aparecen las particularidades del dios, el caprípedo, el bicorne, el amante del ruido, el desgreñado, el de espléndida cabellera; notas que pueden ser vistas en el vaso seleccionado, el cual muestra a Pan recogiendo uvas.

Una segunda dimensión espacial, en donde se pueden observar los distintos ámbitos por donde se destaca la presencia del dios; lugares abiertos, 
rocosos y pastoriles, cumbres de rocas, senderos de cabras, nevosas colinas, cimas de montes y senderos pedregosos, pero también praderas arboladas. Geografías abruptas y llanas, propias de un dios conductor de rebaños y de un dios que, como hemos advertido en la introducción, se mueve en el fino límite entre la civilización y la cultura, entre lo culto y lo no cultivado. La diversidad de espacios parece obedecer a esa misma tensión cualitativa.

Una tercera dimensión asociada a los vínculos que establece; como los sátiros con quienes a menudo es asociado, aparece acompañado por las Ninfas, colectivo femenino, habituado también a los espacios abiertos y a las danzas. Constituyen así una pareja en la que impera el movimiento a través del espacio; movimiento impuesto por la danza, por las idas y venidas y por las acciones propias del pastoreo, bajo su tutela. Compañeros de nomadismo evocan, sin duda, las asociaciones de los sátiros, las ménades y Dioniso, quienes componen un cuadro vivo de actores en escenas habitualmente transidas por el movimiento como nota dominante.

La imagen retorna desde la plasticidad visual de su materialidad.

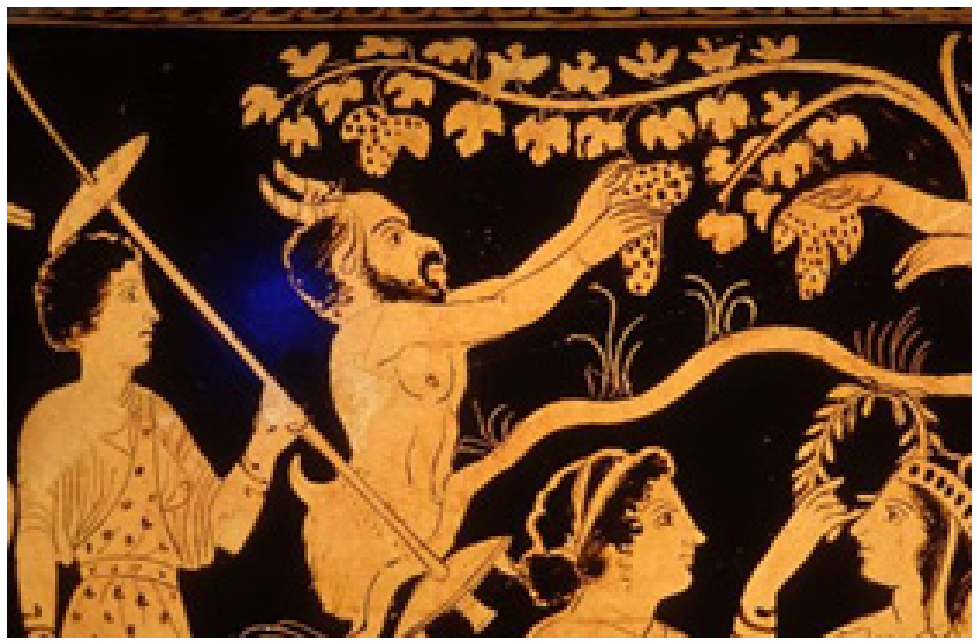

Museum Collection: Toledo Museum of Art, Toledo, Ohio, USA Catalogue Number: Toledo 1981.110 Beazley Archive Number: N/A Ware: Lucanian Red Figure Shape: Volute krater

Painter: Attributed to the Creusa Painter Date: ca 380 - 360 BC Period: Late Classical.

La ménade mira a la derecha, viste un chitón, un himatión, una banda para el cabello, zapatos y brazaletes. Frente a estas dos figuras avanza otra ménade hacia la derecha. Su rostro está de perfil, y usa zapatos, brazaletes y un largo chitón traslúcido con nebris sobre él, ceñido a la cintura, marca que 
la asocia a Dioniso, su Señor. Dos bandas decoran el chitón, una en el ribete y otra con borde punteado corre alrededor de las rodillas. Esta ménade sostiene en su mano izquierda el pie del cótabo que aparece cortando las ancas de Pan; en su mano derecha transporta una sítula.

"Va y viene de aquí para allá por entre los espesos breñales, atraído a veces por las suaves corrientes de un río. A veces, por el contrario, vaga por entre los escarpados roquedales, trepando hasta la más alta cima, atalaya de rebaños" (HOMERO, Himno XIX, 8-11). Los versos aluden nuevamente al nomadismo que venimos tematizando como modo no sólo de enfatizar un rasgo identitario, sino también como manera de asociarlo a Dioniso en su mismo vagabundeo, lo cual implica una utilización del espacio como topos familiar y connatural, apropiado desde una dimensión que hace del movimiento una marca distintiva (DETIENNE, 1986). Este movimiento implica, como en el caso de Dioniso, una imposibilidad de asirlo en un espacio fijo y definitivo. De aquí para allá y la tensión "a veces" dan cuenta de esa inasibilidad propia del dionisismo como fenómeno epifánico.

El topos natural sigue siendo su morada, espesos breñales, especie de maleza y de flora tupida, que surge espontáneamente, que suele dificultar la agricultura, volviendo de difícil tránsito a los terrenos y caminos que invade, suaves corrientes e ríos y escarpados sitios poblados de rocas. El Dios va y viene, vaga y trepa, dueño de lo agreste.

Parece darse una relación indisoluble entre sus rasgos y el espacio como hito instituyente: "A menudo corre través de las altas montañas de resplandeciente blancura. A menudo atraviesa por entre las laderas matando fieras, tras escrutarlas con penetrante mirada" (HOMERO, Himno XIX, 1214)

La dimensión el movimiento se enfatiza con dos acciones que se suman al vagabundeo de los versos anteriores. El Dios corre y atraviesa montañas blancas por sus formaciones calcáreas, y laderas, al tiempo que aparece una nueva dimensión funcional: la caza. Su acción se juega en la tensión entre dos colectivos de animales, las fieras, a quienes mata tras "penetrante mirada", y los rebaños, custodiados desde la cima más alta, "atalaya de rebaños". Dos actitudes, dos modos de vincularse con una naturaleza que parece ser su oikos.

"De vez en cuando, al atardecer, se deja oír él solo de regreso de la montería, tocando suave música con su caramillo. No lo aventajaría en sus cantos el ave que, entre las frondas de la florida primavera, difunde su lamento y derrama su melifluo canto" (HOMERO, Himno XIX, 14-18). Una nueva marca de su dimensión funcional es el canto y la música, que, como sabemos, 
están asociados, al entorno pastoril. Los juegos con la naturaleza persisten y la comparación se da con el ruiseñor, que jamás podría emular su "bello y dulce canto", las mismas cualidades que suele tener el canto de las Musas. La música constituye una dimensión que vuelve a asociarlo con los sátiros y con el cortejo dionisíaco en general, ya que el thíasos en honor al hijo de Seméle está atravesado por la música como elemento constitutivo de la procesión ritual.

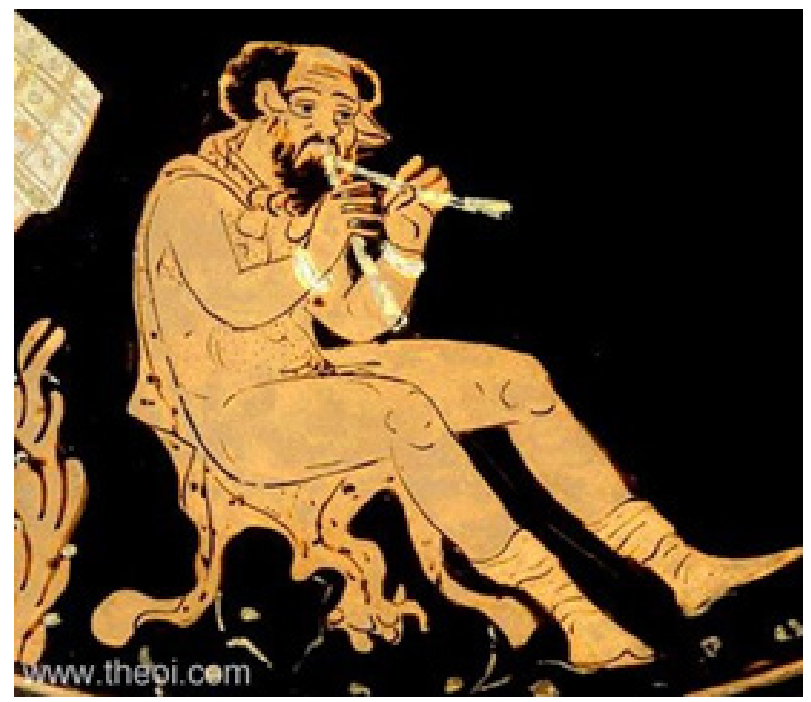

Museum Collection: Musée du Louvre, Paris, France Catalogue Number: Louvre K570 Beazley Archive Number: N/A Ware: Paestan Red Figure Shape: Lekanis lid Painter: Attributed to Asteas Date: ca 360 - 340 BC Period: Late Classical.

La cerámica nos marca otra forma de acceder al tópico, una forma no mediada por el logos tradicional de la palabra; una mirada directa que prioriza la sensibilidad imagética de la representación. La pieza devuelve la imagen de Marcyas, un sátiro tocando la flauta doble y las similitudes con Pan son notorias, ya sea por la dimensión musical como por la estética que la misma exhibe. Las orejas puntiagudas y la barba constituyen los rasgos típicos de Pan, tal como hemos advertido en vasos anteriores, así como esa imagen de borde, de límite ontológico, que fractura las formas conservadas de lo Mismo para erigirse en una extrañeza radical.

Se puede observar una cierta animalización en la figura, las patas de cabra, propias de Pan, las orejas, los cuernos, la apariencia caprina e incluso ciertas imágenes en donde aparece con cola hablan de una figura de la mezcla, de la intersección de reinos. 
Acompañándolo entonces las montaraces Ninfas de límpido canto, moviendo ágilmente sus pies sobre el venero de oscuras aguas, cantan. Y gime el eco en torno a la cima del monte.

El dios, de una parte a otra de los coros, a veces deslizándose al centro, los dispone, moviendo ágilmente los pies. Sobre su espalda lleva una rojiza piel de lince, enorgullecido en su fuero interno por los melodiosos cantos, en el suave prado donde el azafrán y el fragante jacinto se mezclan indistintos con la hierba al florecer (HOMERO, Himno XIX, 19-26).

El canto da cuenta de la nueva función de Pan como conductor de las Musas. Se distingue nítidamente una función de conducción, asociada a una dimensión de poder sobre el colectivo femenino, a quien lleva de una parte a otra enfatizando la imagen del movimiento y las marcas de una procesión inscrita en el escenario del canto y la danza que alegran el escenario natural, aromatizado por el zafrán y el fragante jacinto. La escena es una imagen maravillosa donde los actores interactúan en un clima de alegre festividad. La imagen del cortejo dionisíaco vuelve a aparecer con la convivialidad de Dionisos y sus adoradoras, las bacantes, hábiles en la danza y en la música, que deleitan a su Señor con el ágil movimiento de sus pies al son de sus instrumentos, ataviados todos con sus pieles de corzo, tal como Pan que porta una rojiza piel de lince.

Las Ninfas, como colectivo luminoso, también guardan un cierto parentesco estructural con otro colectivo femenino de idéntica claridad, las Musas, quienes deleitan al padre con su voz delicada y armoniosa. A continuación el coro que el dios conduce da a conocer una serie de pequeñas escenas de carácter amoroso-familiar, siendo significativa la presencia de Hermes que es introducido con sus rasgos identitarios y sus funciones hasta describir el nacimiento de Pan como fruto del amor entre él y una Ninfa.

Cantan a los dioses bienaventurados y al grande Olimpo. De tal modo, y de forma señalada sobre los demás, se referían al raudo Hermes, a cómo es un veloz mensajero para los dioses todos, y cómo llegó a Arcadia, pródiga en veneros, madre de ganados, donde dispone del recinto Cilenio. Allí, aunque era un dios, apacentaba ganados de áspero vellón, en el predio de un varón mortal. Pues florecía en él un lánguido deseo, que le había invadido, de unirse en amor con la ninfa de hermosos bucles, hija de Dríope (HOMERO, Himno XIX, 27-34).

El coro presenta al raudo Hermes, destacando, en primer término, la función del dios como mensajero de los dioses y, en segundo lugar, su 
asociación con el mundo natural y pastoril, como pastor de rebaños. Esta dimensión funcional no parece apta para un dios, sino más bien para un varón mortal; de allí la expresión "aunque era un dios".

El ambiente natural vuelve a poner en contacto a Pan con Dioniso, acostumbrado al vagabundeo por territorios abiertos, más allá de los límites de la ciudad. Si bien no se trata de una divinidad asociada a los rebaños y a su conducción, sí está asociado a la naturaleza y a los topoi extramuros como nota constitutiva de su identidad. El Himno es generoso en la descripción de los escenarios naturales, cosa poco frecuente en este tipo de composiciones.

La metáfora amorosa se consuma con el amor de Hermes por una Ninfa, Dríope, probablemente asociada con el término "encina", "drys", representando así una "ninfa de las encinas", que porta las habituales marcas de belleza que distinguen al colectivo femenino: "Consiguió una florida boda y ella le engendro, en sus moradas, a Hermes un hijo, desde el primer instante prodigioso de verse, caprípedo, bicorne, amante del ruido, de dulce sonrisa" (HOMERO, Himno XIX, 35-37).

El nacimiento de Pan vuele a ubicarnos en el prodigio que representa su figura, con los rasgos que venimos rastreando, en ese particular enclave donde cabalga lo divino y lo animal, capaz de atemorizar e hilvanar la asociación entre Pan y el temor:

Huyó de un salto y abandonó al niño la nodriza, pues sintió temor cuando vio su rostro desagradable, bien barbado.

Mas el raudo Hermes lo tomó en sus brazos, acogedor. Se alegraba extraordinariamente en su fuero interno el dios. Rápidamente ganó las sedes de los inmortales, tras haber envuelto a su hijo en las espesas pieles de una liebre montaraz. Se sentó junto a Zeus y a los demás Inmortales y les presentó a su hijo. Los inmortales todos alegraron naturalmente su corazón, y en especial el báquico Dioniso. Solían llamarlo Pan porque a todos les alegró el ánimo (HOMERO, Himno XIX, 38-47).

La nodriza es el personaje que, con su huida, refleja el pathos aterrador de lo Otro, representado por el caprípedo bicorne, de rostro desagradable, quien, no obstante, guarda en su estructura ambigua y paradojal, el gesto risueño que lo emparenta, una vez más, con Dioniso y la alegre jovialidad que lo caracteriza. Pan derrama su alegría y todos ven su ánimo reconfortado. Figura jovial, semejante a las Musas que, en la Teogonía hesiódica, alegran el corazón del Padre; en este caso, su jovialidad alegra el ánimo de los Inmortales 
Su padre cierra el relato de las pequeñas escenas que el coro se encarga de informar, tomándolo en sus brazos. Se observa la dimensión afectiva de Hermes que lo acoge y se enorgullece de su hijo, presentándolo ante Zeus y los demás Inmortales en gesto paternal, envuelto en mantas de piel de liebre, uno de los animales afines a su condición de pastor y presente en monedas antiguas que reproducían la imagen de Pan.

La mención de Dioniso da cuenta de las líneas de proximidad entre ambas divinidades, punto que ha sido uno de los ejes del presente trabajo, a partir de los múltiples rasgos de asociación que hemos marcado; precisamente por ello queremos cerrar con el mismo vaso con el cual lo abrimos. Si en una cara aparece Pan asociado a la vid, elemento dionisíaco privilegiado, la otra cara devuelve al propio Dioniso en compañía de Ariadna gozando de las delicias del amor y de los viñedos.

Dioniso y Ariadna. Final feliz para uma escena que nos ha enfrentado a nuestras criaturas extremas. Quizás porque es el propio Dioniso esa figura del límite que tensa las relaciones entre Mismo y lo Otro en el campo de la religiosidad griega.

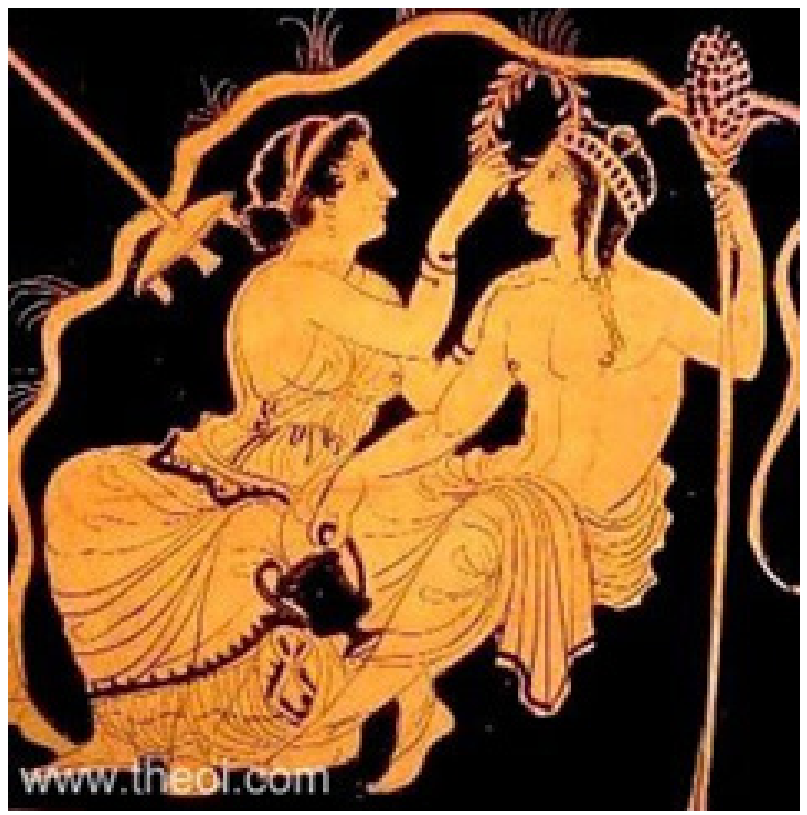

Museum Collection: Toledo Museum of Art, Toledo, Ohio, USA Catalogue Number: Toledo 1981.110 Beazley Archive Number: N/A Ware: Lucanian Red Figure Shape: Volute krater

Painter: Attributed to the Creusa Painter Date: ca 380 - 360 BC Period: Late Classical. 
En el centro Ariadna está sentada a la izquierda con Dioniso a la derecha. Enfrentados, mientras Ariadna sostiene en su mano derecha una corona de laurel que pondrá en su cabeza y con su mano izquierda en el hombro de él, lleva un largo chitón traslúcido sin mangas, a través del cual se hacen visibles sus pechos y la parte de abajo de sus piernas. Usa una banda para sujetar el cabello, brazaletes en ambas muñecas, calzado y un himatión de tejido grueso, recogido alrededor de su falda y rodillas. Una banda recorre el borde inferior del himatión; su borde interno está marcado por puntos espaciados con regularidad. Su vincha está plegada en un rodete en la nuca. Un rizo cuelga frente a su oreja derecha.

Dioniso se sienta con la cabeza algo elevada, como para encontrarse con la corona que Ariadna sostiene sobre él. En su mano izquierda sostiene un tirso y en la derecha un cántaro. Viste un himatión que, al igual que el de Ariadna, se ha deslizado hasta el abdomen. Una banda corre a lo largo del borde inferior de su ropa. Alrededor de su cabeza tiene una vincha decorada con puntos, su extremo está metido debajo de la banda principal en un lazo y una borla que cuelga hacia su hombro.

La culminación del Himno repone la fórmula tradicional de cierre y transición: "Así que te saludo a ti también, soberano. Te propicio con mi canto, pero yo me acordaré además de otro canto y de ti" (HOMERO, Himno XIX, 48-49).

\section{Conclusiones}

El proyecto del presente trabajo consistió en transitar el Himno Homérico XIX a Pan a fin de destacar ciertas marcas de su identidad, así como algunos rasgos funcionales: dios cornudo, con patas de cabra, que sostiene una imagen lasciva que lo territorializa en el confín de la tensión entre el orden natural y el cultural.

Desde la metáfora espacial se lo puede rastrear por distintos ámbitos abiertos, rocosos y pastoriles, cumbres, senderos de cabras, nevosas colinas, cimas de montes y senderos pedregosos, que nos han mostrado su transición lo culto a lo inculto. Especial atención merecieron los vínculos que el dios establece, por ejemplo con los sátiros, las Ninfas y, en particular, con el fenómeno dionisíaco, afín a ciertos rasgos del caprípedo. El movimiento a través del espacio que genera la danza, las idas y venidas y el nomadismo que los atraviesa, fueron algunos de los tópicos relevados para establecer un juego de asociaciones que nos permitió intuir la versatilidad del hijo de Hermes. 
Jugamos deliberadamente con dos órdenes discursivos, la materialidad de la cerámica griega en su plasticidad visual y las marcas textuales de la tradición hímnica.

Pretendimos así poner en circulación dos logoi para saber más del objeto recortado.

\begin{abstract}
The project of the present work consists of traversing the Homeric Hymn XIX to Pan in order to relieve certain identity marks and some functional aspects of Pan, a divinity unknown to Homer and Hesiod who do not name him in his references to the Olympians. He appears as a cuckolded god, with goat's legs, a lascivious, dangerous and irascible image, inscribed on the edge of the tension between nature and culture.

We propose a first approximation to his image of the hand of the ceramic support as a way of crossing two languages, two discursive orders, with their own rules of operation, two logoi that, in their textual cross-linking, will allow us a deeper access to the materiality of the topic. From this perspective, the "vases" speak; constitute a support of imagery that allows us to approach the representation of Pan, analogous to the input that enables us sources, which we will analyze in parallel.
\end{abstract}

Keywords: Pan, Homeric Hymn to Pan, red-figure style, sameness, otherness.

\title{
REFERENCIAS
}

BERNABÉ PAJARES, A. Introducción al Himno XIX. In Himnos Homéricos La Batracomiomaquia. Madrid: Gredos, 2001.

BOEHRINGER S. \& SEBILLOTTE CUCHET V. (dir.). Hommes et femmes dans l'Antiquité grecque et romaine. Le Genre: méthode et documents. Paris: Colin, 2011.

COLOMBANI, M.C. Hesíodo. Una introducción crítica. Buenos Aires: Santiago Arcos, 2005.

COLOMBANI, M. C. Hesíodo. Discurso y Linaje. Una aproximación arqueológica. Mar del Plata: EUDEM, 2016.

COOK, R. M. Greek Painted Pottery (3rd edition), London and New York, Routledge, 1997, pp. 155-157 y 175-177.

DETIENNE, M. Dioniso a cielo abierto. Barcelona: Gedisa, 1986.

HESÍODO. Obras y fragmentos. Madrid: Gredos, 2000.

HOMERO. Ilíada. Madrid: Gredos, 2000.

Theoi Project Copyright 2000-2011, Aaron Atsma: www.theoi.com. 